\title{
Genome plasticity and systems evolution in Streptomyces
}

\author{
Zhan Zhou ${ }^{1,2}$, Jianying $\mathrm{Gu}^{3}$, Yong-Quan $\mathrm{Li}^{1 *}$, Yufeng Wang ${ }^{2,4^{*}}$ \\ From 7th International Symposium on Bioinformatics Research and Applications (ISBRA'11) \\ Changsha, China. 27-29 May 2011
}

\begin{abstract}
Background: Streptomycetes are filamentous soil-dwelling bacteria. They are best known as the producers of a great variety of natural products such as antibiotics, antifungals, antiparasitics, and anticancer agents and the decomposers of organic substances for carbon recycling. They are also model organisms for the studies of gene regulatory networks, morphological differentiation, and stress response. The availability of sets of genomes from closely related Streptomyces strains makes it possible to assess the mechanisms underlying genome plasticity and systems adaptation.
\end{abstract}

Results: We present the results of a comprehensive analysis of the genomes of five Streptomyces species with distinct phenotypes. These streptomycetes have a pan-genome comprised of 17,362 orthologous families which includes 3,096 components in the core genome, 5,066 components in the dispensable genome, and 9,200 components that are uniquely present in only one species. The core genome makes up about $33 \%-45 \%$ of each genome repertoire. It contains important genes for Streptomyces biology including those involved in gene regulation, secretion, secondary metabolism and morphological differentiation. Abundant duplicate genes have been identified, with 4\%-11\% of the whole genomes composed of lineage-specific expansions (LSEs), suggesting that frequent gene duplication or lateral gene transfer events play a role in shaping the genome diversification within this genus. Two patterns of expansion, single gene expansion and chromosome block expansion are observed, representing different scales of duplication.

Conclusions: Our results provide a catalog of genome components and their potential functional roles in gene regulatory networks and metabolic networks. The core genome components reveal the minimum requirement for streptomycetes to sustain a successful lifecycle in the soil environment, reflecting the effects of both genome evolution and environmental stress acting upon the expressed phenotypes. A better understanding of the LSE gene families will, on the other hand, bring a wealth of new insights into the mechanisms underlying strainspecific phenotypes, such as the production of novel antibiotics, pathogenesis, and adaptive response to environmental challenges.

\section{Background}

Streptomyces is a group of Gram positive bacteria ubiquitously inhabiting soil. It is the largest genus in the Actinobacteria, including over 580 species [1]. Streptomycetes are characterized by a large linear chromosome, a rich repertoire of secondary metabolites, and a complex life

\footnotetext{
* Correspondence: lyq@zju.edu.cn; yufeng.wang@utsa.edu

'College of Life Sciences, Zhejiang University, Hangzhou 310058, P. R. China 2Department of Biology, University of Texas at San Antonio, San Antonio, TX 78249, USA

Full list of author information is available at the end of the article
}

cycle alternating between the filamentous vegetative mycelium stage and the spore-bearing aerial hyphae stage. They are best known for their importance in medicine and pharmaceuticals, as their secondary metabolic pathways produce more than half of the bioactive compounds in use, including antibiotics, anticancer agents, antiparasitic drugs, antifungals, immunosuppressants, and herbicides $[2,3]$. They also play a crucial role in maintaining the balance of the biosphere by decomposing the insoluble remains of other organisms such as lignocellulose and chitin. Recently, bacteria in this genus have
C Biomed Central

() 2012 Zhou et al; licensee BioMed Central Ltd. This is an open access article distributed under the terms of the Creative Commons Attribution License (http://creativecommons.org/licenses/by/2.0), which permits unrestricted use, distribution, and reproduction in any medium, provided the original work is properly cited. 
been used in industry as a novel host system for expression of heterogeneous proteins that results in better yields and simpler downstream processing of biotechnology products $[4,5]$.

The deciphering of the genetic code of S. coelicolor, the best studied organism in Streptomyces in 2002 has opened an unprecedented opportunity for systems-wide explorations of cellular components and their interactions [3]. Genome sequencing revealed an exceptional abundance of gene clusters related to antibiotic reproduction, transcriptional regulation and transport. The genome sequence of the second species in this genus, $S$. avermitilis, an industrial strain for avermectin production, was released in 2003 [6]. At the time of writing, the genome sequencing projects of about 30 Streptomyces strains are in various stages of completion.

The availability of sets of genomes from closely related Streptomyces strains makes it possible to assess the mechanisms underlying genome plasticity and systems adaptation. Gene duplication and lateral gene transfer (LGT) are believed to be major evolutionary forces driving the genome evolution in bacteria [7-9]. Gene duplication is of paramount importance for functional innovation. Duplicate genes could have different fates $[10,11]$ : in the case of neofunctionalization, the duplicate copy, which is free of selection, is able to acquire beneficial mutations and eventually evolves a novel function while the original copy retains its original function; in the case of nonfunctionalization, the duplicate copy accumulates deleterious mutations and ultimately becomes a pseudogene; and the third scenario is subfunctionalization when two gene copies diverge and specialize to perform non-overlapping functions. LGT is particularly important for bacteria as it is a general mechanism for them to acquire genetic materials from other organisms via transformation, conjugation, bacterial phage transduction, and acquisition of plasmids $[8,12-14]$. It is well documented that the genes associated with antibiotic resistance and virulence can arise via LGT [15]. Widespread exchange of genetic materials is observed across Streptomyces species, suggesting the significant impact of LGT [16]. Both gene duplication and LGT events could lead to the emergence of multicopy gene families in the genome, some of which show lineage-specific expansions (LSEs) $[9,17,18]$.

In this study, we report a comprehensive comparative genomic analysis of five model species in the genus Streptomyces [3,6,19-21] with complete genome sequences and annotation [22]: (1) S. coelicolor is a model organism for streptomycetes and it can produce a variety of antibiotics, including actinorhodin, CDA (calcium-dependent antibiotic), methylenomycin, and undecylprodigiosin [23]; (2) S. avermitilis [6] produces avermectin which is a potent agent against a wide array of nematodes and arthropod parasites; (3) S. griseus [20] produces streptomycin, a broad-spectrum antibiotic which has been used for the treatment of various diseases such as tuberculosis and the plague caused by Yersinia pestis [24,25]. It has also served as a model system for the study of "tissue" differentiation as a large body of work has been focused on delineating the regulatory mechanisms of morphological differentiation and tightly linked secondary metabolism [26]; (4) S. bingchenggensis produces milbemycin, an antiparasitic agent against worms, ticks and fleas used in veterinary clinics [19]; (5) S. scabiei [21], unlike the majority of streptomycetes which are non-pathogenic, is the causative agent for potato scab, a disease that is responsible for significant economic losses worldwide [21,27].

Our analyses revealed the composition of the pangenome, which includes the core genome - the gene complement present in all the five streptomycetes, the dispensable genome - containing genes present in two or more (but not all) strains, and the unique genes specific to a single strain [28-30]. We showed that lateral gene transfer accompanying gene duplications have marked the evolutionary history of streptomycetes, and the core genome and lineage-specific expanded genome components involve genes that are associated with adaptive phenotypes as well as in the fundamental life cycle of streptomycetes. An evolutionary perspective on the genome components will shed light on the exquisite design of the cellular system as well as the adaptive mechanisms of strain-specific features, including the production of novel antibiotics, pathogenesis, and responses to environmental and physiological stresses.

\section{Results and discussion}

The pan-genome is comprised of 17,362 orthologous families in the five Streptomyces genomes

The Markov clustering algorithm OrthoMCL [31] was used to identify orthologous clusters in the five Streptomyces genomes. This algorithm involves two major subsequent steps: an all-versus-all pairwise BLASTP similarity search and the Markov clustering which clusters the pairs into groups. Two major parameters were used to predict the orthologous groups: the BLASTP cutoff E-value and the Markov clustering inflation index. Figure 1 shows the orthology detection results, using the E-values of 10, 1, 0.1, $0.01,10^{-3}, 10^{-4}, 10^{-5}, 10^{-6}, 10^{-7}, 10^{-8}, 10^{-9}$, and $10^{-10}$, and the inflation indexes of 1.0, 1.5, and 2.0. The number of predicted orthologous groups ranges from 8,341-9,209. Clearly, the lower E-value, the more stringent the detection is and thus the lower false-positive rate. On the other hand, the larger the inflation index, the more tightness of the clustering is and thus the lower false-positive rate. The performance of various orthology detection strategies including OrthoMCL has been rigorously assessed. The effects of parameter alteration on orthology detection 


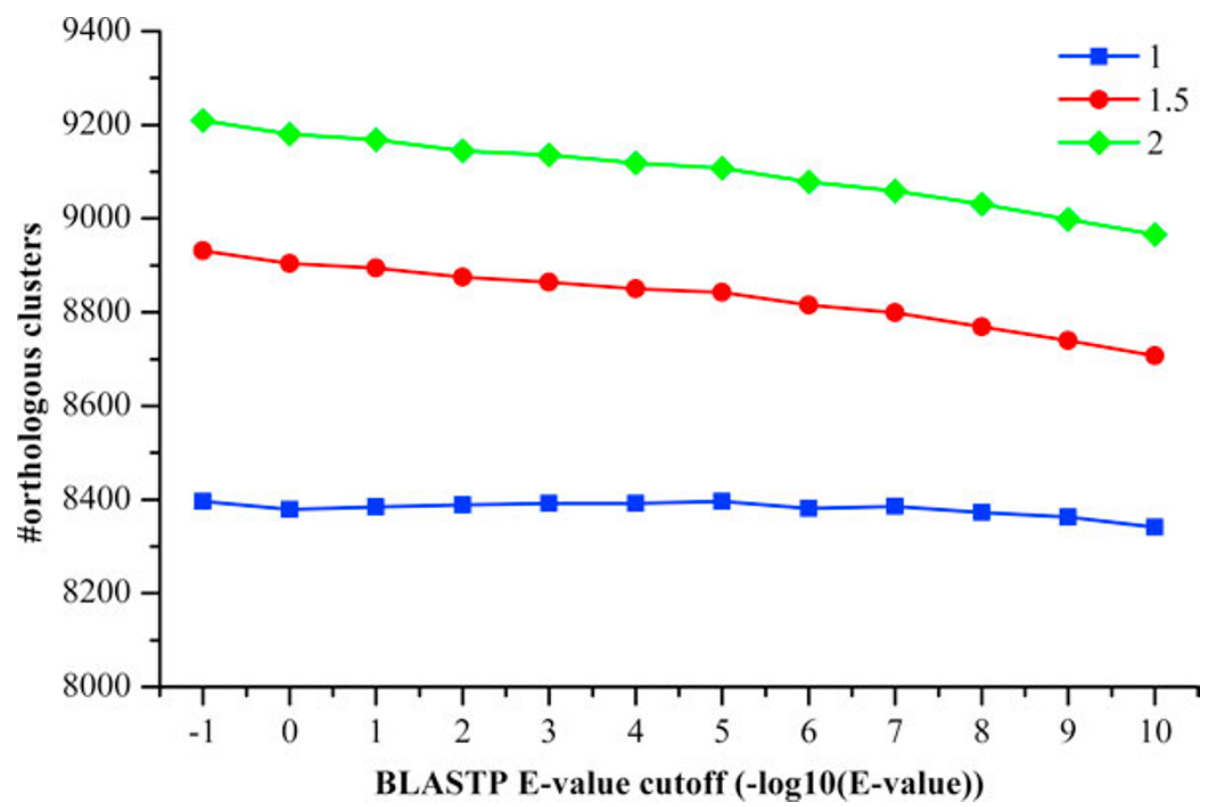

Figure 1 The orthologous clusters identified by OrthoMCL. The parameters include the BLASTP cutoff E-values $\left(10,1,0.1,0.01,10^{-3}, 10^{-4}, 10^{-5}\right.$, $10^{-6}, 10^{-7}, 10^{-8}, 10^{-9}$, and $10^{-10}$ ) and the MCL Markov clustering inflation indexes (1.0, 1.5, and 2.0).

performance were summarized in [32], which suggested a default setting (BLASTP E-value $10^{-5}$ and inflation index 1.5) for achieving high sensitivity and specificity in orthology detection. All of our subsequent analysis and discussions are based on the results using this default setting.

Further analysis of the clusters in the five Streptomyces genomes revealed that 17,362 orthologous families constitute the pan-genome (Figure 2) [29,33], which includes: (1) 3,096 core genome components; (2) 5,066 components in the dispensable genome which have representatives in at least two but not all five genomes; (3) 9,200 components that are uniquely present in only one species. These species-specific genes include 587 lineage-unique LSE gene families and 8,613 singletons [7]. As singleton genes were the focus of original genome papers, we will focus our analysis on the core genome and the lineage-specific expansions.

\section{The core genome of five Streptomyces species}

1) OrthoMCL analysis identified a catalog of the core genome which is comprised by 3,096 orthologous gene families (Additional file 1)

All five streptomycetes contain a large linear chromosome with high GC content (about 70\%). The size of the chromosomes ranges from 8.7 Mbp to 11.9 Mbp (Table 1). Some streptomycetes carry plasmid(s): S. coelicolor A3(2) has a linear plasmid SCP1 and a circular plasmid SCP2, and S. avermitilis has a linear plasmid SAP1. S. bingchenggensis, S. griseus, and S. scabiei do not contain any plasmids.
The proportion of the core genome components in each strain ranges from $33 \%$ to $45 \%$, which is negatively correlated to the number of open reading frames (ORFs) in each genome (Table 1). S. bingchenggensis appears to have the lowest proportion (33\%) as it has the largest genome (11.9 Mbp) and the largest number of ORFs $(10,023)$. It could be indicative of its higher level of sequence divergence, or could be an underestimation due to its incomplete and preliminary annotation status [19].

Among the 3,096 orthologous families, 2,765 (89\%) contain only a single representative from each species, and the remaining 331 orthologous families have multiple copies in at least one genome. Orthologous families are designated by "strep" followed by four digits in our following discussions. Strep1001 and strep1003 are the two largest multigene families, with 104 and 46 homologs respectively: the former encodes type I polyketide synthases (PKSs) [34], which catalyze the biosynthesis of a variety of secondary metabolites with industrial importance; and the latter encodes non-ribosomal peptide synthetases (NRPSs) [35], which are responsible for the biosynthesis of nonribosomal peptides, including toxins, siderophores, and pigments that are used as antibiotics, cytostatics, and immunosuppressants. The gene copy numbers vary significantly from genome to genome. For example, S. coelicoler contains only four members of the cluster strep1001, while S. bingchenggensis has 51 homologs. Similarly, in S. scabiei there are only four copies of the cluster strep1003, whereas 19 copies are found in S. bingchenggensis. This observation not only suggests 


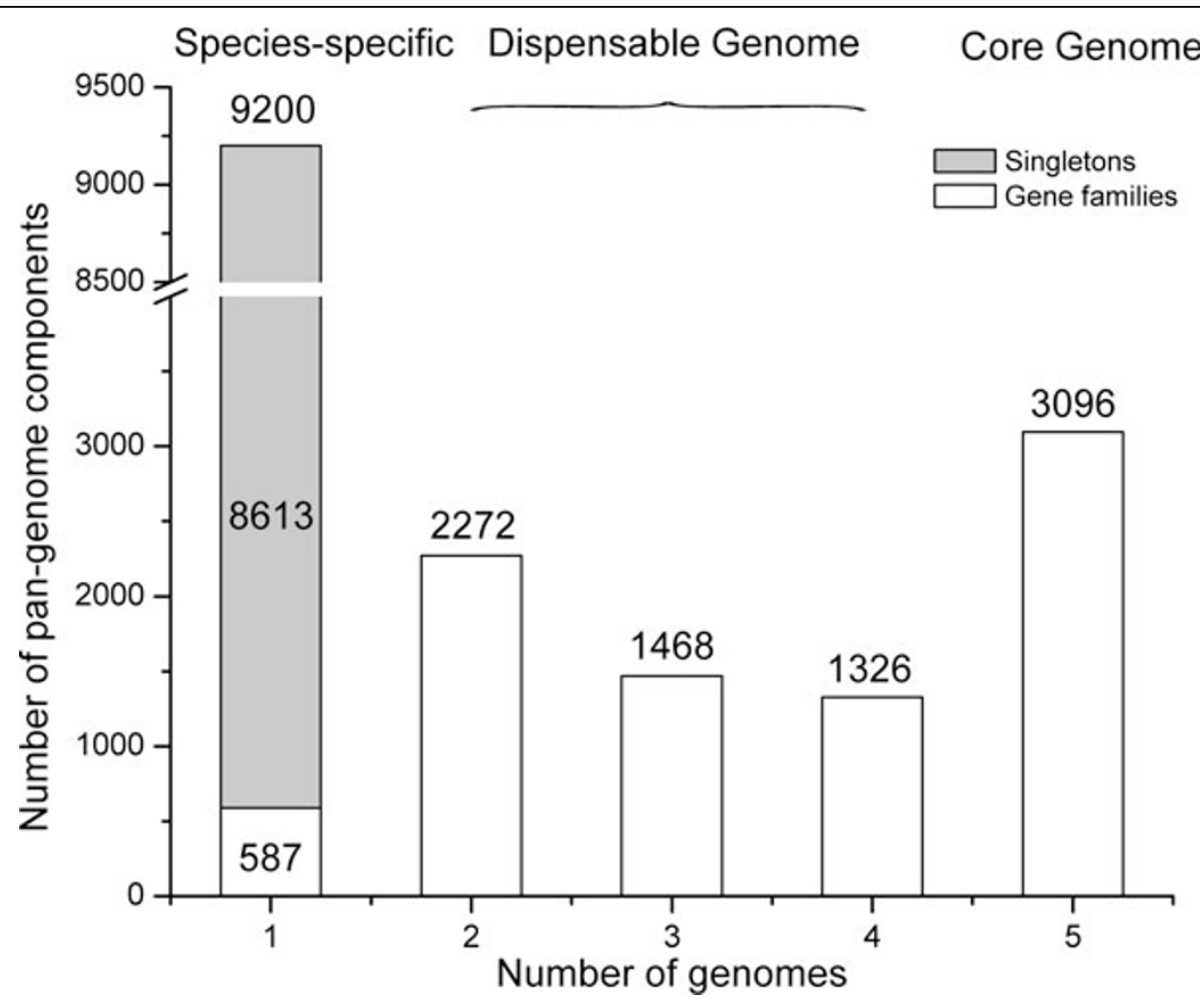

Figure 2 The pan-genome of five Streptomyces species.

that it is likely that the machinery for biosynthesis of natural products is inherited from their common ancestor as an adaptive trait for surviving in adverse environment, but also suggests that these streptomycetes have evolved strain-specific modules of secondary metabolic pathways for competition, self-defense, signaling and cell-to-cell communication [36].

We identified Streptomyces signature proteins by BLAST scanning the core genome. Fifty gene families appear to be specific to streptomycetes, and $62 \%$ of these (31/50) are annotated as hypothetical proteins with no functional assignment (Additional file 2). More than $90 \%$ of these signature genes are located in the central (core) region of the chromosome. Thirteen gene families encode putative secreted proteins or membrane proteins. The gene families strep4549 and strep4767 encode lipoprotein. Strep1957 encodes the SpdB protein, a mobile element transfer protein that was shown to enhance the efficiency of plasmid

Table 1 The core genome components and lineage-specific expansions (LSEs) in five Streptomyces species.

\begin{tabular}{|c|c|c|c|c|c|c|c|c|}
\hline \multirow[t]{2}{*}{ Strains } & \multirow[t]{2}{*}{ Accession ID } & \multirow{2}{*}{$\begin{array}{c}\text { Genome size } \\
\text { (Mbp) }\end{array}$} & \multirow{2}{*}{$\begin{array}{l}\text { \# Genes (\# ORFs) in } \\
\text { genome }\end{array}$} & \multirow{2}{*}{$\begin{array}{l}\% \text { core in } \\
\text { genome }\end{array}$} & \multicolumn{2}{|c|}{ \# LSE families } & \multirow{2}{*}{$\begin{array}{l}\text { \# LSE } \\
\text { genes }\end{array}$} & \multirow{2}{*}{$\begin{array}{l}\% \text { LSEs in } \\
\text { genome }\end{array}$} \\
\hline & & & & & $\begin{array}{l}\text { Lineage- } \\
\text { unique }\end{array}$ & $\begin{array}{l}\text { Typical } \\
\text { LSEs }\end{array}$ & & \\
\hline S. avermitilis MA- 4680 & $\begin{array}{l}\text { NC_003155 (chr) } \\
\text { NC_004719 } \\
\text { (plasmid SAP1) }\end{array}$ & 9.1 & 7765 (7676) & 41.87 & 38 & 112 & 312 & 4.06 \\
\hline $\begin{array}{l}\text { S. bingchenggensis } \\
\text { BCW-1 }\end{array}$ & CP002047 (chr) & 11.9 & 10025 (10023) & 33.35 & 219 & 232 & 1127 & 11.24 \\
\hline S. coelicolor A3(2) & $\begin{array}{c}\text { NC_003888 (chr) } \\
\text { NC_003903 } \\
\text { (plasmid SCP1) } \\
\text { NC_003904 } \\
\text { (plasmid SCP2) }\end{array}$ & 9.1 & $8300(8153)$ & 39.42 & 98 & 163 & 568 & 6.97 \\
\hline S. griseus IFO 13350 & NC_010572 (chr) & 8.5 & 7224 (7136) & 44.63 & 116 & 105 & 471 & 6.60 \\
\hline S. scabiei $87-22$ & NC_013929 (chr) & 10.1 & 8901 (8746) & 36.47 & 116 & 186 & 689 & 7.88 \\
\hline
\end{tabular}

The inter-genomic search yielded a core genome comprised of 3,096 orthologous proteins. 
transfer [37]. Strep4112 encodes two-component system sensor kinase/response regulators, which play diverse roles in signal transduction, gene regulation, and morphological differentiation. Strep4486 encodes serine/threonine protein kinases. Strep3256 encodes proteins related to carbohydrate transport. These Streptomyces signature proteins represent distinctive molecular and physiological characteristics of streptomycetes.

\section{(2) The functional categories of the core genome components}

$2,236(72 \%)$ gene families in the core genome were predicted to have at least one Gene Ontology annotation [38], with a total of $11,399 \mathrm{GO}$ annotations within 1,189 GO categories based on their molecular function, biological process involved, and the subcellular location. The two most abundant GO functional categories are catalytic activity (GO:0003824) and metabolic process (GO:0008152), which include 484 and 457 gene families respectively, representing a substantial percentage $(16 \%$ and $15 \%$ ) of the core genome components. Moreover, 303 gene families in the core genome are predicted to have transfersase activity (GO:0016740), constituting the most abundant class of the enzymes in the core genome. These statistics reflect the most distinctive characteristics of streptomycetes: a powerful biochemical machinery with a magnitude unusually large number for biosynthesis and biotransformation [3]. Table 2 lists examples of functional categories in the core genome critical for Streptomyces biology.

(i) Genetic information processing Abundant orthologous gene families in the core genome are related to genetic information processing in the framework of the central dogma: 27 gene families are involved in DNA replication (GO:0006260), 174 families are associated with the transcriptional process and regulation (GO:0006350), and 102 families are related to translation (GO:0006412). Also within the core genome are a group of gene families that are implicated in genetic material exchange: 14 families are involved in DNA recombination (GO:0006310), among which four families are likely to confer transposase activity (GO:0004803) and two families are related to DNA integration (GO:0015074). This observation suggests that lateral gene transfer also plays a role in the emergence of the Streptomyces core genome [16].

(ii) The complex gene regulatory network Streptomycetes are well known for their remarkable capability for gene regulation. The large number of regulatory proteins that govern the gene expression in a temporal- and spatial-specific manner underscores this capability. It was reported that 965 regulation-related proteins are in the S. coelicolor genome, accounting for about $12 \%$ of the ORFs [3]. Our comparative analysis revealed that 263 gene families in the core genome are related to DNAdependent regulation of transcription (GO:0006355), 201 of which may have sequence-specific DNA binding transcription factor activity (GO:0003700) and 43 families could have specific transcriptional repressor activity (GO:0016566). The master regulators of critical importance in streptomycetes include a set of sigma factors which serve as transcription initiation factors, enabling specific binding of RNA polymerase to the promoter region of target genes. S. coelicolor and S. aveimitilis both have over 60 sigma factors [3,6], outnumbering most of the bacteria which generally have $<20$ sigma factors. Our analysis identified 31 gene families in the core genome which have putative sigma factor activity (GO:0005525). Notably, 20 of these families encode the ECF (extracytoplasmic function) sigma factors $[39,40]$, which regulate gene expression in response to environmental challenges. In addition to the ECF sigma factors, streptomycetes harbor powerful two-component transcriptional regulator systems which can globally activate or repress gene transcription in response to extracellular stimulus. Each of these systems consists of a transmembrane histidine protein kinase and a cognate DNA-binding response regulator. The core genome of the five Streptomyces contains 85 gene families that are related to two-component signal transduction system (GO:0000160), including 49 members of two-component sensor (GO:0000155) and 36 members of two-component response regulator (GO:0000156) [41]. These transcriptional regulators are the central coordinators in the life cycle of streptomycetes, contributing significantly to the processes involving the secondary metabolism and morphological differentiation.

(iii) Secondary metabolic process The production of secondary metabolites in Streptomyces is mediated by the biosynthetic gene clusters. The number of gene clusters for secondary metabolism in the five Streptomyces genomes ranges from 23 to 37 [3,6,19-21,42,43]. As the detailed information for each secondary metabolite gene cluster (i.e., chromosome location and predicted/known product) is yet to be published for S. bingchenggensis, our subsequent discussion is focused on the remaining four genomes.

A remarkable percentage of the core genome is attributed to the secondary metabolite gene clusters, $20 \%$ in S. coelicolor, $25 \%$ in S. avermitilis, $19 \%$ in S. griseus and $25 \%$ in S. scabiei, respectively. These four genomes share 20 gene families pertinent to secondary metabolism in the core genome, including 19 families that encode enzymes As mentioned above, strep1001 (type I PKS) and strep1003 (NRPS), the two largest gene families, both encode enzymes crucial for antibiotic production. Eight of these 19 enzyme families encode putative transferases catalyzing reactions involving various types of substrates. For example, strep1833 encodes 3-oxoacyl-ACP (Acyl Carrier Protein) synthases III, strep3082 and strep3561 encode acetyltransferases, strep3083 encodes aminotransferases, 
Table 2 Examples of functional categories of core genome components in five Streptomyces genomes.

\begin{tabular}{|c|c|c|}
\hline Function description & Examples of GO classes & $\begin{array}{r}\text { No. } \\
\text { families }\end{array}$ \\
\hline \multirow{6}{*}{$\begin{array}{l}\text { Genetic information } \\
\text { processing }\end{array}$} & GO:0006260 (DNA replication) & 27 \\
\hline & GO:0006350 (transcription) & 174 \\
\hline & GO:0006412 (translation) & 102 \\
\hline & GO:0006310 (DNA recombination) & 14 \\
\hline & GO:0004803 (transposase activity) & 4 \\
\hline & GO:0015074 (DNA integration) & 2 \\
\hline \multirow[t]{5}{*}{ Regulation } & GO:0003700 (sequence-specific DNA binding transcription factor activity) & 201 \\
\hline & GO:0016566 (specific transcriptional repressor activity) & 43 \\
\hline & GO:0000155 (two-component sensor activity) & 36 \\
\hline & GO:0000156 (two-component response regulator activity) & 49 \\
\hline & GO:0016987 (sigma factor activity) & 31 \\
\hline \multirow[t]{5}{*}{ Metabolism } & GO:0005975 (carbohydrate metabolic process) & 67 \\
\hline & GO:0009058 (biosynthetic process) & 66 \\
\hline & GO:0009116 (nucleoside metabolic process) & 13 \\
\hline & GO:0006520 (cellular amino acid metabolic process) & 12 \\
\hline & GO:0006631 (fatty acid metabolic process) & 7 \\
\hline \multirow[t]{4}{*}{ Morphogenesis } & GO:0007047 (cellular cell wall organization) & 14 \\
\hline & GO:0007059 (chromosome segregation) & 9 \\
\hline & GO:0000902 (cell morphogenesis) & 3 \\
\hline & GO:0000917 (barrier septum formation) & 2 \\
\hline \multirow[t]{4}{*}{ Response to stimulus } & GO:0006950 (response to stress) & 22 \\
\hline & GO:0046677 (response to antibiotic) & 12 \\
\hline & GO:0009432 (SOS response) & 9 \\
\hline & GO:0006979 (response to oxidative stress) & 3 \\
\hline \multirow[t]{6}{*}{ Transport } & GO:0006811 (ion transport) & 14 \\
\hline & GO:0015904 (tetracycline transport) & 9 \\
\hline & GO:0015031 (protein transport) & 8 \\
\hline & GO:0006817 (phosphate transport) & 6 \\
\hline & GO:0006865 (amino acid transport) & 6 \\
\hline & GO:0008643 (carbohydrate transport) & 6 \\
\hline \multirow[t]{8}{*}{ Hydrolase } & GO:0008233 (peptidase activity) & 38 \\
\hline & GO:0016810 (hydrolase activity, acting on carbon-nitrogen (but not peptide) bonds) & 22 \\
\hline & GO:0004553 (hydrolase activity, hydrolyzing O-glycosyl compounds) & 19 \\
\hline & GO:0016788 (hydrolase activity, acting on ester bonds) & 12 \\
\hline & $\begin{array}{l}\text { GO:0016820 (hydrolase activity, acting on acid anhydrides, catalyzing transmembrane movement of } \\
\text { substances) }\end{array}$ & 10 \\
\hline & GO:0016799 (hydrolase activity, hydrolyzing N-glycosyl compounds) & 7 \\
\hline & GO:0030245 (cellulose catabolic process) & 3 \\
\hline & GO:0004568 (chitinase activity) & 2 \\
\hline \multirow[t]{4}{*}{ lon binding } & GO:0008270 (zinc ion binding) & 52 \\
\hline & GO:0051536 (iron-sulfur cluster binding) & 45 \\
\hline & GO:0000287 (magnesium ion binding) & 29 \\
\hline & GO:0005506 (iron ion binding) & 26 \\
\hline
\end{tabular}

and strep5306 and strep 5307 encode phytoene synthases for production of a carotenoid pigment.

Six secondary metabolite gene clusters are conserved in the core genome, including three clusters that contain only one gene: (a) strep5131 is related to the production of geosmin, a compound responsible for the earth smell generated by streptomycetes [44]; (b) strep3625 encodes a 4-hydroxyphenylpyruvate dioxygenase that can produce the orchronotic pigment in S. avetmitilis; (c) most importantly, strep2366 encodes a $\gamma$-butyrolactone 
biosynthesis enzyme (namely ScbA in S. coelicolor and AfsA in S. griseus). $\gamma$-butyrolactone is a hormone-like signaling molecule in Streptomyces, which can trigger morphological differentiation or/and secondary metabolic processes [45]. A-factor is a specific $\gamma$-butyrolactone that has been well studied in S. griseus [46]. Our analysis showed that many components in the A-factor signaling cascade are conserved in the five Streptomyces genomes, including at least seven gene families functioning in a chronological order (strep 1890, strep 2366, strep 3567, strep4078, strep2310, strep1012, and strep8592) [26]: strep1890 contains an A-factor receptor ArpA, which can block the expression of AdpA (strep3567) during the growth of vegetative mycelium. Upon the activation of Afactor biosynthesis by strep2366, A-factor is accumulated, which will release the expression of AdpA (strep3567), an ECF sigma factor that can trigger the downstream effector proteins that are essential for morphological differentiation (strep4078, strep2310, and strep1012) and secondary metabolism (strep8592) [47,48]. The remaining three secondary metabolite clusters with multiple composite genes are for the biosynthesis of 5-hydroxyectoine (strep3082-3085), desferrioxamine (strep35593562), and hopene (strep5306-5310), which are the common natural products of streptomycetes. Figure 3 shows a schematic diagram of the 5-hydroxyectoine cluster (strep3082-3085). More gene clusters are speciesspecific, each with unique products. For example, actinorhodin and undecylprodigiosin are genetic markers for $S$. coelicolor due to their distinct colors. Similar examples include avermectin in S. avermitilis, streptomycin in S. griseus, milbemycin in S. bingchenggensis, and thaxtomin and concanamycin, the plant toxins associated with virulence in S. scabiei [27]. Discussions of these gene clusters are detailed in literature $[3,6,19,20,42,43]$ and therefore they will not be repeated here.

Biosynthesis of secondary metabolites is an extraordinary complex process controlled by a variety of regulatory factors. Not surprisingly, the core genome contains a large number of components related to the regulation of secondary metabolism. Depending on their scope of regulation, they can be pathway-specific, pleiotropic, or global regulators $[49,50]$. For example, strep5198 encodes a pathway-specific transcriptional activator belonging to the Streptomyces antibiotic regulatory protein (SARP) family, which is located in specific secondary metabolite clusters and functions as a switch for the onset of the production of the target antibiotic [49]. Many of the pleiotropic regulators are members of the two-component stimulus-response regulatory systems and are conserved in the core genome; one of their functions is to coordinate the production of antibiotics. For example, the AfsK/AfsR system, a serine/threonine phosphorylation system, is conserved in the core genome: its interacting pairs, a protein serine/threonine kinase AfsK and the target protein AfsR, are the members of the gene families strep4320 and strep2322, respectively. Evidently, AfsK/ AfsR system plays multiple roles in Streptomyces biology; it was shown to be a key regulator of secondary metabolism in S. coelicolor, and essential for morphological differentiation in S. griseus [51]. While they remain to be defined [50], the roles of master regulators-sigma factors in secondary metabolism have begun to be unraveled by several independent research groups: Zhuo et al. [52] showed that mutation of a house-keeping sigma factor HrdB (strep5047) enhanced the production of avermectins in S. avermitilis; we previously reported that SigK (strep2110) [53] and SigT (strep4050) [54] were both involved in the regulation of antibiotic production and morphological development in S. coelicolor.

Another core genome orthologous family, strep2841, encodes a ppGpp synthetase (RelA). ppGpp is a signaling molecule that is involved in the stringent response, and its synthesis triggers downstream antibiotic biosynthesis under stress conditions such as nitrogen starvation in S. coelicolor [55].

(iv) Morphogenesis Streptomycetes are model organisms for developmental biology as they exhibit a complex life

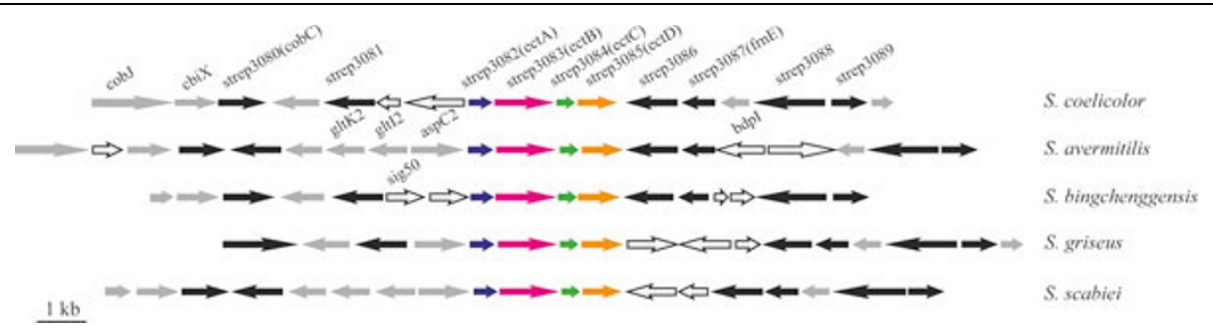

Figure 3 A schematic diagram showing the 5-hydroxyectoine biosynthesis gene cluster (strep3082-3085) that is conserved in the five Streptomyces genomes. The chromosome location of this cluster in each respective genome is: SCO1857-1873 for S. coelicolor, SAV_6407-6388 for S. avermitilis, SBI_08140-08124 for S. bingchenggensis, SGR_5639-5623 for S. griseus, SCAB_70821-70641 for S. scabiei. Blue: strep3082 (ectA), L2,4-diaminobutyric acid acetyltransferase; magenta: strep3083 (ectB), L-2,4-diaminobutyrate aminotransferase; green: strep3084 (ectC), ectoine synthase; orange: strep3085 (ectD), ectoine hydroxylase; black: core genome components; gray: dispensable genome components; white: species-specific genes. 
cycle similar to filamentous fungi, beginning with spore germination, followed by the growth of vegetative mycelium, and the formation of aerial hyphae [26]. Cell morphogenesis of streptomycetes is governed by a series of gene families such as fts, whi, ssg and mre [26]. Our analysis identified 29 gene families in the core genome that are related to cell division (GO:0051301), including the members of the fts and ssg families. More specifically, 14 and nine gene families are involved in cell wall organization (GO:0007047) and chromosome segregation (GO:0007059), respectively, two important processes in cell division. For example, during sporulation, the bacterial homologue of tubulin, FtsZ (strep3217) assembles into a ring structure. This Z-ring determines the division plane and recruits other cell division proteins [56], including FtsQ (strep3218), FtsW (strep3220), and FtsH (strep3876). The subsequent segregation of multiple copies of the linear chromosome into individual copies is regulated by ParA (strep2320), ParB (strep4045) and FtsK/SpoIIIE proteins (strep1874 and strep4996) [26,57]. Moreover, MreB (strep3403) [58] and Mcl (strep3486) [59] are classified into cell morphogenesis process (GO:0000902), both of which are involved in sporulation of the aerial hyphae. Strep 3010 and strp3214 encode SepF homologues which may be related to the mechanism for barrier septum formation (GO:0000917); SepF was shown to be associated with the stability of Z-ring in E. coli and B. subtilis [26].

In addition to cell division proteins, we identified a group of regulatory proteins in the A-factor signaling cascade that controls the formation of aerial mycelium and spores [45]. For example, the core genome has the key proteins for morphological differentiation that are regulated by a master transcriptional activator AdpA: $\sigma^{\text {AdsA }}$ (strep2310), a ECF sigma factor [60]; SgmA (strep1012), a metalloendopeptidase griselysin which is required for aerial mycelium formation, and SsgA (strep4078), an uncharacterized protein essential for sporulation septation [61]. The master regulators in the whi family, which are believed crucial for sporulation of aerial hyphae, have also been identified in the core genome: WhiG (strep4938) which encodes a sigma factor; WhiH (strep5046) which encodes a repressor; WhiI (strep5113) which encodes a two-component regulator; WhiA (strep3138), WhiB (strep3685) and WhiD (strep4478). Two other sigma factors that are important for sporulation, BldD (strep2821) [62] and SigF (strep4128) [63] are also present in the core genome [26].

(v) Response to environmental challenges Streptomycetes predominantly live in soil, facing extremely diverse environmental challenges. The core genome includes 22 gene families that are involved in response to stress (GO:0006950). Interestingly, streptomycetes that are antibiotic producers also have anti-antibiotic genes; 12 families in the core genome are related to responses to antibiotic (GO:0046677), for example, encoding transmembrane efflux pumps. Nine families in the core genome are related to the SOS response (GO:0009432) and three families are involved in responses to oxidative stress (GO:0006979).

(vi) Secretion Streptomycetes secrete a huge number of compounds into the soil via their powerful transport systems. The core genome contains 170 gene families that are participated in the transport process (GO:0006810). 88 families have putative transporter activity (GO:0055085), among which, 81 families are involved in transmembrane transport (GO:0055085). More specifically, based on the substrate specificity, 14 gene families are for ion transport (GO:0006811), six for phosphate transport (GO:0006817), and six for carbohydrate transport (GO:0008643). Notably, nine gene families that are predicted to transport tetracycline (GO:0015904) are in the core genome, which may play a role in the antibiotic efflux process.

Protein translocation is very important in streptomycetes. Eight gene families in the core genome are related to protein transport (GO:0015031). Strep2137 encodes SecA, and strep4445 encodes SecY, which are the essential components of the Sec pathway, a general pathway for exporting unfolded proteins in bacteria [64]. Strep2933 and strep2934 encode TatC and TatA, respectively, which are the key members of the TAT (twin-arginine translocation) pathway which transports prefolded proteins and a group of hydrolytic enzymes in streptomycetes $[65,66]$.

(vii) Hydrolase Streptomycetes are versatile decomposers that play a crucial role in global carbon recycling because they express and secrete a large number of hydrolases, such as chitinase and cellulase, to the extracellular environment to degrade organic matter, especially biopolymers such as lignocellulose and chitin from the insoluble remains of other organisms [3]. The core genome harbors an extensive array of hydrolases which constitute 211 gene families (GO:0016787) that act on a wide range of substrates: 38 families hydrolyze peptide bonds (GO:0008233); 22 families act on carbon-nitrogen (but not peptide) bonds (GO:0016810); 19 families hydrolyze O-glycosyl compounds (GO:0004553); 12 families act on ester bonds (GO:0016788); 10 families act on acid anhydrides (GO:0016820), and seven families hydrolyze N-glycosyl compounds (GO:0016799). In particular, strep2786 and strep4600 have predicted chitinase activities (GO:004568); strep2563, strep2564 and strep3793 are involved in cellulose catabolic processes (GO:0030245).

\section{The Lineage-Specific Expansions (LSEs) in five Streptomyces species \\ (1) The distribution of LSEs}

The comparative analysis of five Streptomyces genomes revealed genes that are specifically expanded in certain lineage(s). Two types of LSE gene families are present in 
these genomes: (a) lineage-unique LSEs, where genes are duplicated in only one unique genome and there are no orthologs in any other other genomes; (b) typical LSEs that are formed from a gene for which at least one ortholog is found in at least one other of the genomes studied. The distributions of these two LSE patterns are summarized in Table 1. Extensive LSEs are found in streptomycetes, which account for $4 \%-11 \%$ of the genome (see Table 1 for the summary and Additional file 3 for detailed gene lists). S. bingchenggensis possesses the largest proportion of duplicate genes among the five stains, with 1,127 LSE genes (about 11\%) of the whole genome, reflecting a rich history of gene duplication or lateral gene transfer events that could possibly lead to its larger genome size. S. coelicolor, S. griseus and S. scabiei have much smaller proportion of LSE genes than $S$. bingchenggensis, ranging from $7 \%$ to $8 \%$, and S. avermitilis contains the smallest proportion of all; only $4 \%$ of its genome is composed of LSE genes, among which only 38 gene families appear to be lineage-unique LSEs.

\section{(2) The patterns of lineage-specific expansions}

The size of the LSE gene families ranges from two to 75 copies, but the majority of them consist of only a small number of gene copies ( $\leq 10$ copies). About 81\%-97\% of the gene families in each Streptomyces species consist of two paralogous genes. Only 25 LSE families have more than five duplicate gene copies in S. coelicolor, S. bingchenggensis and S. scabiei, eight of which encode integrases or transposases, hallmarks of extensive lateral gene transfer events. The largest LSE gene families ( $>10$ copies) are only found in S. bingchenggensis (Figure 4).

These LSEs show two distinct patterns on chromosome arrangement. The first pattern involves contiguous expansion of a single gene, which leads to multiple copies of a gene in a consecutive order on the chromosome (Table 3). A striking example is seen in strep1002, the largest LSE gene family, containing 75 paralogous genes in S. bingchenggensis, where 14 blocks of 33 duplicate genes are located adjacently. Their gene products are related to DNA integration and transposition. Similarly, SCO34663467 (strep1777), SBI_09333-09334 (strep1016) and SCAB_42921-42931 (strep1854) encode two adjacent copies of transposases in S. coelicolor, S. bingchenggensis and S. scabiei. The gene families with potential roles as transcriptional regulators or secreted proteins also show contiguous expansion. For example, SAV_576-577 (strep8429) encode TetR family transcriptional regulators in S. avermitilis, which are pleiotropic repressors implicated in biosynthesis of antibiotics, drug efflux or osmotic stress [67]. In S. scabiei, SCAB_48881-48891 (strep7064) and SCAB_81001-81011 (strep8654) encode transcriptional repressors in the GntR family [68] and the IclR family [69], respectively. S. coelicolor has 12 contiguous
LSEs. Three families SCO0445-0446 (strep8395), SCO7774-7775 (strep5410) and SCO7791-7791a (strep6870) encode secreted proteins, including an extracellular oxidoreductase; SCO2906-2907 (strep2302) and SCO5663-5664 (strep2354) encode transmembrane proteins.

The second pattern of LSEs is at a larger scale, involving the duplication of blocks of genes rather than a single gene (Table 4). Block duplications tend to accumulate at the terminal inverse repeats (TIRs) $[70,71]$ of the S. coelicolor, S. griseus, and S. scabiei chromosomes and S. coelicolor plasmid SCP1, with block sizes from 15 to 126. We have discussed the TIR LSE distribution and its impact on genome instability elsewhere [72]. Eighty-six block duplications occurred in the chromosomal regions other than TIRs. The majority of the duplicate blocks span from two to seven genes. We identified an exceptionally large block in S. scabiei, which includes two sets of duplicate genes, each containing at least 58 genes (SCAB_21721-22561, SCAB_32241-33211), whereas S. coelicolor only has a single set (SCO6924-6843), and the other three species do not seem to have them as a set (Figure 5). Most of the genes in this chromosomal block are hypothetical proteins with no identified or characterized functionality. There are 24 block duplicate genes in S. scabiei. Interestingly, five blocks of two genes are distributed discontiguously on the chromosome (SCAB_0371-0372, SCAB_0691-0692, SCAB_0991-0982, SCAB_23721-23722, SCAB_90821-90812), with four located in the terminal regions (Table 4). The two duplicate genes encode a conserved hypothetical protein and a putative IS transposase, indicating that influx of the seed gene was mediated by a type of lateral gene transfer.

(3) The functional categories of lineage-specific expansions

553 of the 1385 LSE gene families in the Streptomyces genomes did not have any GO annotation and were predominantly annotated as hypothetical proteins. More experimental evidence is needed to determine their functions. The remaining $832(60 \%)$ LSE gene families with GO annotation provide species-specific evolutionary profiles of streptomycetes. Some examples, drawn from the families our analysis uncovered, follow.

(i) Transcriptional regulation We identified 131 LSE gene families that may play a role in DNA-dependent transcriptional regulation (GO:0006355), 59 of which are lineage-unique. Notably, 39 families are part of the twocomponent signal transduction system (GO:0000160); the genesis of these lineage-specific domain structures in this elaborate signaling system was likely triggered by different external stimuli [41]. Thirteen families encode sigma factors (GO:0016987). The fact that all of them are ECF sigma factors suggests that lineage-specific radiation of master regulators is an adaptive response to different ecological and physiological cues and stresses. 


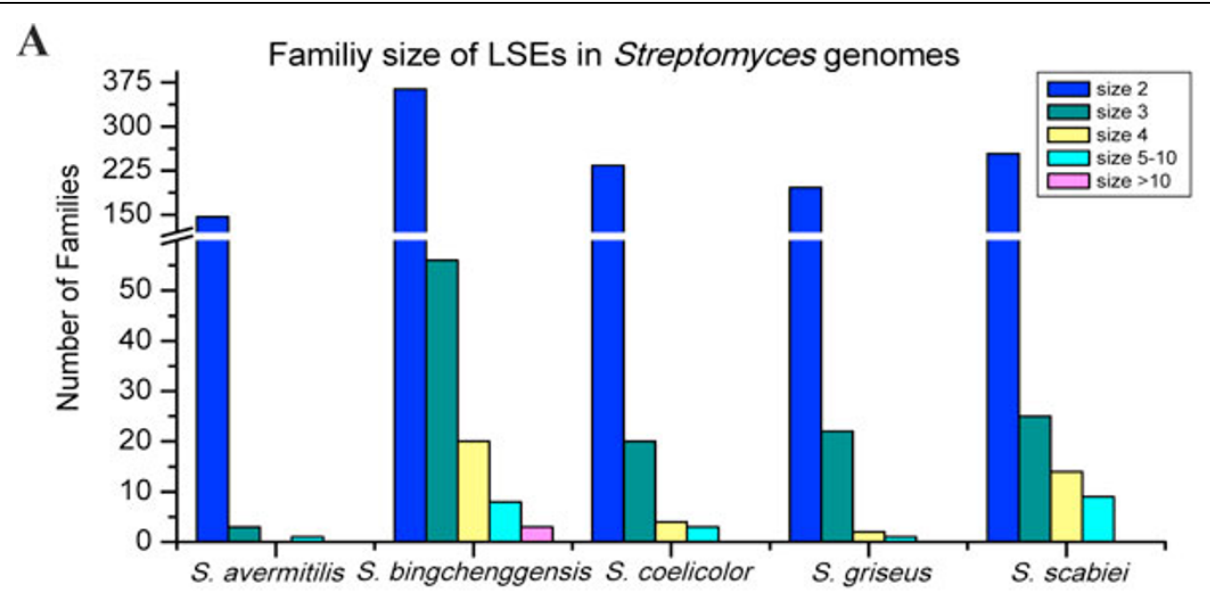

B

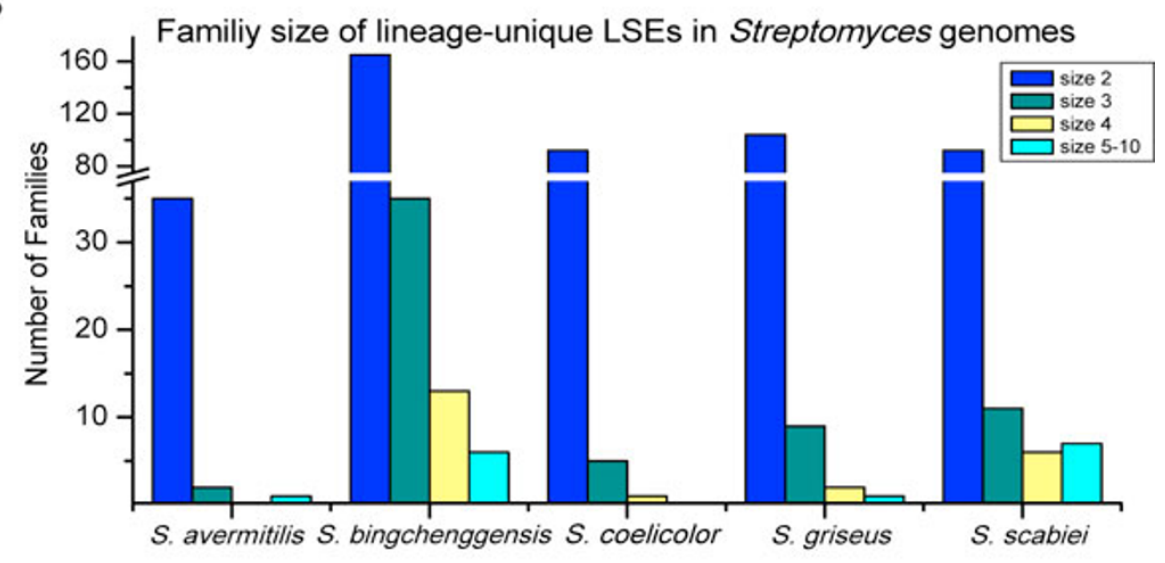

C

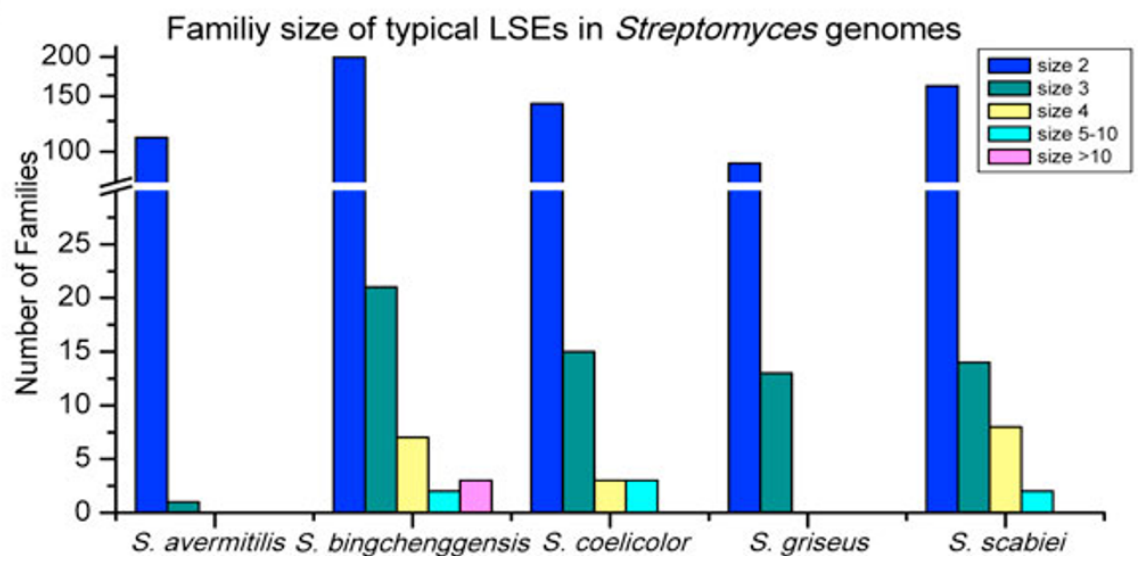

Figure 4 The distribution of gene families with lineage-specific expansions in five Streptomyces species. A. Distribution of the size of LSE gene families. B. Distribution of the size of lineage-unique LSE gene families. C. Distribution of the size of typical LSE gene families.

S. bingchenggensis has the most abundant supply of lineage-unique LSE families (32) of transcriptional regulators, significantly outnumbering the other four species. These gene families generally have two or three paralogous genes. Six gene families encode two-component system regulators; five encode TetR family transcriptional regulators
[67], which were shown to have dual roles in antibiotic production and sporulation [73]; five encode the LacI family transcriptional repressors that are implicated in carbohydrate metabolism, nucleoside transport and utilization [74]; one family (strep8527) encodes a ECF sigma factor. The rich repertoire of LSEs in S. bingchenggensis suggests 
Table 3 Examples of contiguous single gene expansions in five Streptomyces genomes.

\begin{tabular}{|c|c|c|c|}
\hline Stains & Family & Duplications & Function description \\
\hline \multirow[t]{6}{*}{ S. coelicolor $(11)^{\mathrm{a}}$} & strep1777 & SCO3466-3467 & Transposase \\
\hline & strep2302 & SCO2906-2907 & PTS transmembrane protein \\
\hline & strep2354 & SCO5663-5664 & Integral membrane protein \\
\hline & strep5410 & SCO7774-7775 & Secreted protein \\
\hline & strep6870 & SCO7791-7791a & Secreted oxidoreductase \\
\hline & strep8395 & SCO0445-0446 & Secreted protein \\
\hline \multirow[t]{2}{*}{ S. avermitilis (5) } & strep8429 & SAV576-577 & TetR family transcriptional regulator \\
\hline & strep2207 & SAV5346-5349 & Hypothetical protein \\
\hline \multirow[t]{9}{*}{ S. bingchenggensis (15) } & strep1002 & 14 groups & DNA integration \\
\hline & strep1016 & SBI_09333-09334 & Transposase \\
\hline & strep2168 & SBI_06671-06672 & Integral membrane protein \\
\hline & strep2332 & SBI_06321-06322 & Regulatory protein \\
\hline & strep2438 & SBI_04627-04628 & Regulatory protein \\
\hline & strep5446 & SBI_02610-02611 & Cytochrome P450 family protein \\
\hline & strep5448 & SBI_02692-02693 & Beta galactosidase \\
\hline & strep8479 & SBI_01576-01577 & Transcriptional regulator, $\mathrm{CdaR}$ \\
\hline & strep8554 & SBI_09566-09567 & NmrA family protein \\
\hline \multirow[t]{4}{*}{ S. griseus (5) } & strep2491 & SGR_2433-2434, SGR_5023-5024 & Hypothetical protein \\
\hline & strep7090 & SGR_4733-4734 & Membrane transporter \\
\hline & strep8591 & SGR_812-813 & FAD-dependent oxidoreductase \\
\hline & strep8821 & SGR_605-606 & Putative enediyne biosynthesis protein \\
\hline \multirow[t]{6}{*}{ S. scabiei (10) } & strep1854 & SCAB_42921-42931 & Transposase \\
\hline & strep5499 & SCAB_23621-23631 & Oxidoreductase \\
\hline & strep5512 & SCAB_42581-42591 & Integrin-like protein \\
\hline & strep7062 & SCAB_69611-69621 & Extracellular substrate-binding protein \\
\hline & strep7064 & SCAB_48881-48891 & GntR family transcriptional regulator \\
\hline & strep8654 & SCAB_81001-81011 & ICIR family transcriptional regulator \\
\hline
\end{tabular}

Note: ${ }^{\text {a }}$ The number in parenthesis shows the number of LSE families with contiguous single gene expansions in each genome.

the evolution of its transcriptional regulation network is likely driven by niche-specific signals.

(ii) Oxidoreductase The continuously changing soil environment presents strong redox challenges to streptomycetes. We identified 111 LSE families with potential oxidoreductase activity (GO:0016491), 39 of which are lineage-unique. The cytochrome P450 (CYP) family is a group of monooxygenases that play important roles in diverse oxidative processes that require iron ion binding (GO:0005506). CYP is over-represented in streptomycetes compared to other bacteria [75], and the repertoire includes six LSE gene families (strep2300, strep5360, strep5846, strep2157, strep5446 and strep6906). In addition to their generic redox function, these CYP enzymes were shown to facilitate secondary metabolism by biosynthetic tailoring of natural products [76] whose structural engineering may lead to novel antibiotics in streptomycetes. Another important class of proteins, including 29 LSE families, are involved in redox activity that requires zinc ion binding (GO:0008270).

(iii) Transferases Transferases are important enzymes for metabolism, especially for secondary metabolism in streptomycetes. For example, phosphopantetheinyl transferases are required for biosynthesis of polyketides and non-ribosomal peptides [77], aminotransferases play a key role in biosynthesis of aminoglycoside antibiotics [78], and glycosyltransferases are involved in glycosylation of various natural products [79]. We identified 63 LSE gene families with putative transferase activities (GO:0016740). Eighteen families exhibit lineage-unique radiation, including three glycosyltransferase families. For example, strep2169 encodes six paralogous proteins involved in lipid glycosylation in S. bingchenggensis. S. avermitilis and S. griseus also have a lineage-unique LSE glycosyltransferase family. Strep7009 encode three paralogous aminotransferases in S. scabiei.

(iv) Hydrolases Streptomycetes are prodigious producers of hydrolases that catalyze the hydrolysis of a wide variety of chemical bonds. We identified 70 LSE gene families with putative hydrolase activity (GO:0016787). Twentyseven families are lineage-unique, including 10 families of glycosyl hydrolases, which are important for carbon source acquisition in various environments. Most significantly, two lineage-unique LSE families encode proteins 
Table 4 Examples of LSE block duplications in five Streptomyces genomes.

\begin{tabular}{|c|c|c|}
\hline Strains & $\begin{array}{l}\text { Block } \\
\text { size }\end{array}$ & Blocks \\
\hline S. coelicolor & 5 & (SCO3264-3266, SCO3268-3269)(SCO3986-3984, SCO3982-3981) \\
\hline \multirow[t]{4}{*}{$(13)^{\mathrm{a}}$} & 4 & (SCO0216-0219)(SCO4947-4950)(SCO6535-6532) \\
\hline & 4 & (SCO4525-4528)(SCOSCP1.168-171) \\
\hline & 3 & (SCO1603-1605)(SCO6400-6402) \\
\hline & 2 & (SCO0874-0875)(SCO3521-3522) \\
\hline S. avermitilis & 7 & (SAV_354-360)(SAV1008-1011, SAV_1013-1015) \\
\hline \multirow[t]{4}{*}{ (9) } & 4 & (SAV_5337-5340)(SAV7154, SAV7150-7148) \\
\hline & 3 & (SAV_4095-4097)(SAV_5434-5432) \\
\hline & 2 & $($ SAV_1199-1200)(SAV_7454-7453) \\
\hline & 2 & (SAV_7567-7568)(SAP1p22-21) \\
\hline $\begin{array}{c}\text { S. } \\
\text { bingchenggensis }\end{array}$ & 7 & 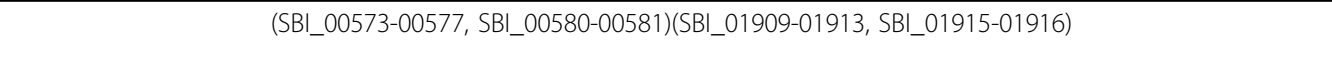 \\
\hline \multirow[t]{9}{*}{ (34) } & 4 & (SBI_02525-02528)(SBI_06733-06736) \\
\hline & 4 & (SBI_04407-04410)(SBI_04411-04414) \\
\hline & 3 & (SBI_00377-00379)(SBI_05209-05211) \\
\hline & 3 & (SBI_00539-00541)(SBI_05182-05184) \\
\hline & 2 & (SBI_00043-00044)(SBI_07509-07510)(SBI_07927-07928)(SBI_07929-07930) \\
\hline & 2 & (SBI_02527-02528)(SBI_05511-05510)(SBI_07028-07029)(SBI_07426-07425) \\
\hline & 2 & (SBI_03820,03822)(SBI_03854-03855)(SBI_07225-07226) \\
\hline & 2 & (SBI_00058-00059)(SBI_04127-04128)(SBI_05638-05637) \\
\hline & 2 & (SBI_04480-04481)(SBI_04484-04485) \\
\hline S. griseus & 2 & (SGR_443-444)(SGR_6579-6578) \\
\hline \multirow[t]{3}{*}{ (4) } & 2 & (SGR_454-455)(SGR_4567-4566) \\
\hline & 2 & (SGR_2409-2410)(SGR_2414-2415) \\
\hline & 2 & (SGR_2951-2950)(SGR_4306-4305) \\
\hline \multirow[t]{8}{*}{ S. scabiei (24) } & 58 & $\begin{array}{l}\text { (SCAB_21721-21811, 21981-22181, 22201-22281, 22331, 22351-22371, 22391-22401, 22421-22481, 22501, 22531-22561) } \\
\quad \text { (SCAB_32241-32331, 32561-32811, 32831-32861, 32991, 33031-33071, 33061- 33071, 33091-33141, 33161-33211) }\end{array}$ \\
\hline & 5 & (SCAB_10401-10441)(SCAB_76871-76841) \\
\hline & 4 & (SCAB_0501-0531)(SCAB_84341-84311) \\
\hline & 3 & (SCAB_4431-4451)(SCAB_88631-88611) \\
\hline & 2 & (SCAB_0371-0372)(SCAB_0691-0692)(SCAB_0991-0982)(SCAB_23721-23722) (SCAB_90821-90812) \\
\hline & 2 & (SCAB_0831-0841)(SCAB_1341-1351)(SCAB_10021-10011)(SCAB_81311-81301) \\
\hline & 2 & (SCAB_2791-2801)(SCAB_5601-5591)(SCAB_88151-88161) \\
\hline & 2 & (SCAB_13971-13981)(SCAB_14051-14061) \\
\hline
\end{tabular}

Block size describes the number of genes in chromosomal or plasmid region that has been duplicated together.

Note: ${ }^{a}$ The number in parenthesis shows the number of duplicated gene blocks in each genome.

related to pathogenesis in the plant pathogen S. scabiei: strep8867 encodes an expansin-like protein, which is able to mediate acid-induced extension in plant cell walls; strep8868 contains a gene SCAB_78931 encoding an extracellular cutinase. Both expansin and cutinase may have a role in plant pathogenesis by damaging the plant defense system [27].

(v) Transport As discussed above, an extraordinary diverse transport machinery is a critical adaptive trait of streptomycetes. We identified 77 LSE gene families that are related to transport. Sixteen LSE families are lineageunique, and six belong to the ABC (ATP-binding cassette) transporter superfamily. Members of the $A B C$ superfamily frequently prove to be multidrug efflux pumps, because members of this family, such as P-glycoproteins, are known to facilitate resistance to a wide array of compounds including therapeutic agents. $\mathrm{ABC}$ transporters are abundant in streptomycetes and they can be classified into three groups based on the number and organization of the nucleotide-binding domains and transmembrane domains [80]. These LSE families encode $A B C$ transporters in the antibiotic biosynthesis clusters which may play a role in the antibiotic secretion as well as the evolution of drug resistance. SGR_443 (in the family strep8583) and SGR_444 (in strep8584) encode member proteins of an NRPS gene cluster for the production of peptidic siderophores [42]. These two proteins fall into the same clade phylogenetically with other Type III ABC transporters 


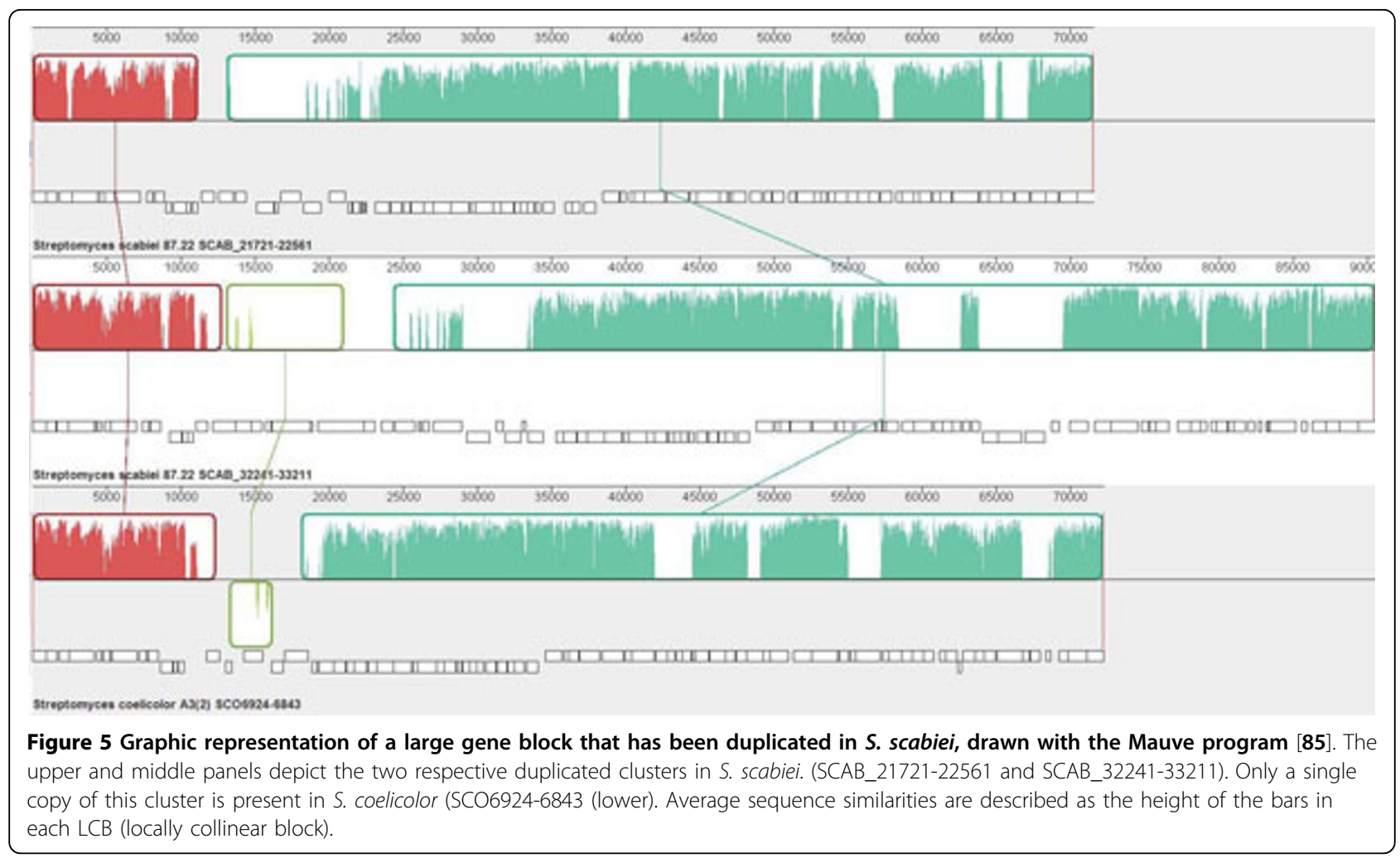

with proved or predicted involvement in drug resistance in multiple Streptomyces species (Figure 6) [80]. A BLAST search against the transporter classification database (TCDB) [81] showed that both proteins have high sequence similarity to known multidrug transporters. Moreover four LSE families were predicted to be involved in tetracycline transport (GO:0015520) in S. avermitilis, $S$. bingchenggensis, S. griseus, and S. scabiei.

(vi) Transposition and integration Abundant transposases and integrases, the two characteristic types of enzymes involved in lateral gene transfer, are present in a lineage-specific expanded manner in the five Streptomyces genomes. The length of the transposases varies, ranging from 34 aa to 783 aa, representing truncated, frameshifted or full-length version of the enzymes. Seventeen LSE gene families were predicted with putative transposase activity, including several large families that have at least five paragolous genes in one genome. For example, strep1002 exhibits a radiation of 75 members in S. bingchenggensis. Many of these transposase genes are located in the terminal regions of the chromosome. Twelve LSE gene families are involved in DNA integration. It was previously reported that homologous recombination is widespread in streptomycetes, and the intraspecies recombination rate is even larger than the interspecies rate [16]. A high degree of transposition and integration can lead to either acquisition of new genetic material or homologous replacement of existing genes, which could contribute to chromosome expansion or genome plasticity.

\section{Conclusions}

Comparative genomic analysis of the five Streptomyces species revealed a pan-genome with 17,362 orthologous families which includes 3,096 components in the core genome, 5,066 components in the dispensable genome, and 9,200 components that are uniquely present in only one species.

The core genome contains important genes for Streptomyces biology including those involved in the complex regulation networks and powerful secretion systems. Many genes related to secondary metabolism and morphological differentiation are also conserved in streptomycetes indicating that these five strains share a common or similar mechanism for carrying out these two processes which are both under the control of nutritional conditions such as carbon, nitrogen, and phosphorous nutrients.

We also identified abundant lineage-specific expanded gene families, suggesting that frequent gene duplication or lateral gene transfer events play a role in shaping the genome diversification within this genus. Two patterns of expansion, single gene expansion and chromosome block expansion are observed, representing different scales of 


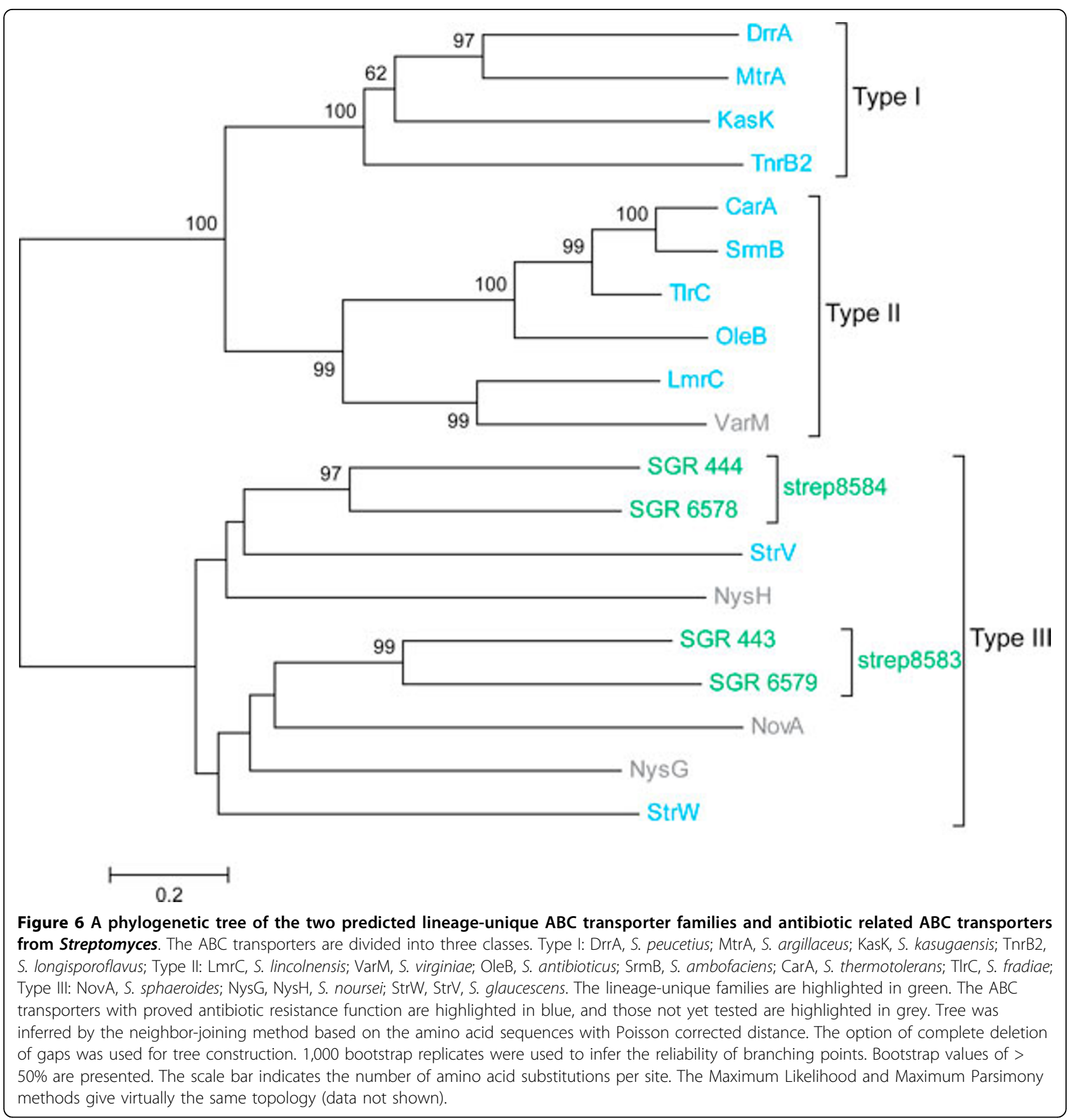

duplication. The degree of the LSEs, and the functional categories of the amplified genes vary between species: S. bingchenggensis, which has the largest genome among these five species, contains the largest proportion of LSE genes, and most abundant LSE transcriptional regulators; S. scabiei has amplified hydrolases that are implicated in plant virulence; S. griseus contains a number of ABC transporters that have potential roles in antibiotic transport and drug resistance. Deciphering the patterns and functional roles of these LSE gene families provides valuable clues as to how bacteria develop strain-specific adaptive phenotypes, ranging from diverse secondary metabolism, to sophisticated morphological differentiation, pathogenesis, and effective responses to endogenous and exogenous signals.

The evolutionary systems biology approach is readily adapted to any system for which genome sequences of evolutionarily related species/strains exist, offering promises to unveil the design principles and evolutionary mechanisms of biodiversity. 


\section{Methods \\ Data}

We collected the five completed Streptomyces genomes (Table 1) from NCBI http://www.ncbi.nlm.nih.gov/genome/browse/. The data for nucleotides, proteins and annotations (Jan 1, 2011) were downloaded.

\section{Sequence similarity search and identification of homologous gene families}

All-versus-all BLASTP search of all protein sequences from the five Streptomyces genomes was conducted to identify the presence of homologous genes (including orthologous and paralogous), using the NCBI BLASTP [82]. Homologous genes, both from the same and different genomes, were clustered into groups, using the OrthoMCL algorithm [31] (Version 2.0, http://www.orthomcl.org). OrthoMCL uses Markov clustering to identify groups from an allagainst-all protein similarity graph and it was shown to achieve both high sensitivity and specificity in orthology detection [32]. Two parameters were adjusted in our analysis: the BLASTP cutoff E-value was set to be 10, 1, 0.1, $0.01,10^{-3}, 10^{-4}, 10^{-5}, 10^{-6}, 10^{-7}, 10^{-8}, 10^{-9}$, and $10^{-10}$, and the Markov clustering inflation index was set to be 1.0, 1.5, and 2.0, while the default setting was E-value $=10^{-5}$, and inflation index $=1.5$ [31].

To identify the Streptomyces signature proteins, we conducted BLASTP search with the core genome components against the non-redundant protein sequences (nr) database excluding the Streptomyces genus, using the NCBI BLAST. A protein was considered as Streptomyces signature protein if there was no BLAST hits with acceptable E-values $\left(<10^{-5}\right)$, similarity $(>30 \%)$ and coverage $(>50 \%)$.

Multiple alignments were obtained by ClustalX 2.1 [83], and phylogenetic trees were inferred by MEGA5 with neighbor-joining, maximum parsimony and maximum likelihood method [84]. Mauve 2.3.1 was used to illustrate the alignment pattern of the block expansions [85].

\section{Functional classification analysis}

Functional annotation of each gene from the five genomes was obtained by mapping against the Gene Ontology Annotation (GOA) database at the European Bioinformatics Institute (EBI) ftp://ftp.ebi.ac.uk/pub/ databases/GO/goa[38], which provides hierarchical annotations for gene products based on their associated molecular function, biological process and their subcellular locations [22]. The GOA provides high-quality GO annotations for over 160,000 taxa. Full GO annotations are completed for over 1,700 proteomes including the five Streptomyces species under this study [38]. The specificity of transporters was predicted by searching against the Transporter Classification Database (TCDB) [81].

\section{Additional material}

Additional file 1: The core genome of five Streptomyces species. A core genome of five Streptomyces genomes comprised of 3,096 orthologous clusters is listed. GO functional classification and gene descriptions are also included.

Additional file 2: Streptomyces signature proteins in the core genome.

Additional file 3: Lineage Specific Expansions (LSEs) in five Streptomyces species. The lineage-unique LSES and typical LSES are presented in the second and third worksheets respectively.

\section{List of abbreviations used}

ABC: ATP-Binding Cassette; CDA: calcium-dependent antibiotic; EBI: European Bioinformatics Institute; ECF: extracytoplasmic function; GO: Gene Ontology; GOA: Gene Ontology Annotation; LCB: locally collinear block; LGT: lateral gene transfer; LSE: lineage-specific expansion; nr: non-redundant protein sequences; NRPS: non-ribosomal peptide synthetase; ORF: open reading frame; PKS: polyketide synthase; TAT: twin-arginine translocation; TCDB: transporter classification database.

\section{Acknowledgements}

This article has been published as part of BMC Bioinformatics Volume 13 Supplement 10, 2012: "Selected articles from the 7th International Symposium on Bioinformatics Research and Applications (ISBRA'11)". The full contents of the supplement are available online at http://www. biomedcentral.com/bmcbioinformatics/supplements/13/S10.

This work is supported by NIH grants GM081068, Al080579, and Al067543 to YW, NSFC grants 30870033 and 31070040 to YQL, and the PSC-CUNY Research Award PSCREG-41-892 to JG. YW is also supported by an NIH grant RR013646. ZZ is supported by the government scholarship from China Scholarship Council. We thank Drs. Yudong Li and Yiling Du for technical assistance and critical reading of this manuscript. We thank the

Computational Biology Initiative at UTSA for providing computational support. The content is solely the responsibility of the authors and does not necessarily represent the official views of the National Institute of General Medical Sciences, National Institute of Allergy and Infectious Diseases, National Center for Research Resources, the National Institutes of Health or Natural Science Foundation of China.

\section{Author details}

${ }^{1}$ College of Life Sciences, Zhejiang University, Hangzhou 310058, P. R. China. 2Department of Biology, University of Texas at San Antonio, San Antonio, TX 78249, USA. ${ }^{3}$ Department of Biology, College of Staten Island, City University of New York, Staten Island, NY 10314, USA. ${ }^{4}$ South Texas Center for Emerging Infectious Diseases, University of Texas at San Antonio, San Antonio, TX 78249, USA.

\section{Authors' contributions}

YW, YQL and ZZ conceived and designed the study. JG wrote the scripts. $Z Z$, JG and YW performed data analysis. YW and ZZ drafted the manuscript. All authors read and approved the final manuscript.

\section{Competing interests}

The authors declare that they have no competing interests.

Published: 25 June 2012

\section{References}

1. Garrity GM, Lilburn TG, Cole JR, Harrison SH, Euzéby J, BJ T: Part 10 - The Bacteria: Phylum "Actinobacteria": Class Actinobacteria. Taxonomic Outline of the Bacteria and Archaea 2007, Release 7.7:399-539.

2. Hopwood DA: Streptomyces in Nature and Medicine: The Antibiotic Makers. New York: Oxford University Press; 2007.

3. Bentley SD, Chater KF, Cerdeno-Tarraga AM, Challis GL, Thomson NR, James KD, Harris DE, Quail MA, Kieser H, Harper D, et al: Complete genome 
sequence of the model actinomycete Streptomyces coelicolor A3(2). Nature 2002, 417(6885):141-147.

4. Li YD, Zhou Z, Lv LX, Hou XP, Li YQ: New approach to achieve high-level secretory expression of heterologous proteins by using Tat signal peptide. Protein Pept Lett 2009, 16(6):706-710.

5. Vrancken $K$, Anné J: Secretory production of recombinant proteins by Streptomyces. Future Microbiology 2009, 4(2):181-188.

6. Ikeda H, Ishikawa J, Hanamoto A, Shinose M, Kikuchi H, Shiba T, Sakaki Y, Hattori M, Ōmura S: Complete genome sequence and comparative analysis of the industrial microorganism Streptomyces avermitilis. Nat Biotechnol 2003, 21(5):526-531.

7. Gevers D, Vandepoele K, Simillion C, Van de Peer Y: Gene duplication and biased functional retention of paralogs in bacterial genomes. Trends Microbiol 2004, 12(4):148-154

8. Ochman H, Lawrence JG, Groisman EA: Lateral gene transfer and the nature of bacterial innovation. Nature 2000, 405(6784):299-304.

9. Gu J, Neary J, Cai H, Moshfeghian A, Rodriguez SA, Lilburn TG, Wang Y: Genomic and systems evolution in Vibrionaceae species. BMC Genomics 2009, 10(Suppl 1):S11.

10. Lynch M, Conery JS: The evolutionary fate and consequences of duplicate genes. Science 2000, 290(5494):1151-1155.

11. Lynch M: Genomics. Gene duplication and evolution. Science 2002, 297(5583):945-947.

12. Andam CP, Gogarten JP: Biased gene transfer in microbial evolution. Nat Rev Microbiol 2011, 9(7):543-555.

13. Babic A, Berkmen MB, Lee CA, Grossman AD: Efficient gene transfer in bacterial cell chains. MBio 2011, 2(2)

14. Treangen TJ, Rocha EP: Horizontal transfer, not duplication, drives the expansion of protein families in prokaryotes. PLOS Genet 2011, 7(1): e1001284

15. Barlow M: What antimicrobial resistance has taught us about horizontal gene transfer. Methods Mol Biol 2009, 532:397-411.

16. Doroghazi JR, Buckley DH: Widespread homologous recombination within and between Streptomyces species. ISME J 2010, 4(9):1136-1143.

17. Cai H, Gu J, Wang Y: Core genome components and lineage specific expansions in malaria parasites Plasmodium. BMC Genomics 2010, 11(Suppl 3):S13.

18. Jordan IK, Makarova KS, Spouge JL, Wolf YI, Koonin EV: Lineage-specific gene expansions in bacterial and archaeal genomes. Genome Res 2001, 11(4):555-565.

19. Wang XJ, Yan YJ, Zhang B, An J, Wang JJ, Tian J, Jiang L, Chen YH, Huang $S X$, Yin $M$, et al: Genome Sequence of the Milbemycin-Producing Bacterium Streptomyces bingchenggensis. J Bacteriol 2010, 192(17):4526-4527.

20. Ohnishi $Y$, Ishikawa J, Hara H, Suzuki H, Ikenoya M, Ikeda H, Yamashita A, Hattori M, Horinouchi S: Genome Sequence of the StreptomycinProducing Microorganism Streptomyces griseus IFO 13350. J Bacteriol 2008, 190(11):4050-4060.

21. Yaxley AM: Study of the complete genome sequence of Streptomyces scabies (or scabiei) 87.22. University of Warwick; 2009

22. Ashburner M, Ball CA, Blake JA, Botstein D, Butler H, Cherry JM, Davis AP, Dolinski K, Dwight SS, Eppig JT, et al: Gene ontology: tool for the unification of biology. The Gene Ontology Consortium. Nat Genet 2000, 25(1):25-29.

23. Kieser T, Bibb MJ, Buttner MJ, Chater KF, Hopwood DA: Practical Streptomyces Genetics. Norwich, England: John Innes Foundation; 22000.

24. Distler J, Mansouri K, Mayer G, Stockmann M, Piepersberg W: Streptomycin biosynthesis and its regulation in Streptomycetes. Gene 1992, 115(12):105-111.

25. Mansouri K, Piepersberg W: Genetics of streptomycin production in Streptomyces griseus: nucleotide sequence of five genes, strFGHIK, including a phosphatase gene. Mol Gen Genet 1991, 228(3):459-469.

26. Flardh K, Buttner MJ: Streptomyces morphogenetics: dissecting differentiation in a filamentous bacterium. Nat Rev Microbiol 2009, 7(1):36-49.

27. Bignell DRD, Huguet-Tapia JC, Joshi MV, Pettis GS, Loria R: What does it take to be a plant pathogen: genomic insights from Streptomyces species. Anton Leeuw Int J G 2010, 98(2):179-194.

28. Medini D, Donati C, Tettelin H, Masignani V, Rappuoli R: The microbial pangenome. Curr Opin Genet Dev 2005, 15(6):589-594.
29. Lefébure T, Stanhope MJ: Evolution of the core and pan-genome of Streptococcus: positive selection, recombination, and genome composition. Genome Biol 2007, 8(5):R71.

30. Richards VP, Lang P, Pavinski Bitar PD, Lefebure T, Schukken YH, Zadoks RN, Stanhope MJ: Comparative genomics and the role of lateral gene transfer in the evolution of bovine adapted Streptococcus agalactiae. Infect Genet Evol 2011.

31. Li L, Stoeckert CJ Jr, Roos DS: OrthoMCL: identification of ortholog groups for eukaryotic genomes. Genome Res 2003, 13(9):2178-2189.

32. Chen F, Mackey AJ, Vermunt JK, Roos DS: Assessing performance of orthology detection strategies applied to eukaryotic genomes. PLOS One 2007, 2(4):e383.

33. Lefebure T, Bitar PD, Suzuki H, Stanhope MJ: Evolutionary dynamics of complete Campylobacter pan-genomes and the bacterial species concept. Genome Biol Evol 2010, 2:646-655.

34. Staunton J, Weissman KJ: Polyketide biosynthesis: a millennium review. Nat Prod Rep 2001, 18(4):380-416.

35. Marahiel MA, Essen LO: Chapter 13. Nonribosomal peptide synthetases mechanistic and structural aspects of essential domains. Methods Enzymol 2009, 458:337-351.

36. Chater KF, Biro S, Lee K, Palmer T, Schrempf H: The complex extracellular biology of Streptomyces. FEMS Microbiol Rev 2010, 34(2):171-198.

37. Kataoka M, Seki T, Yoshida T: Regulation and function of the Streptomyces plasmid pSN22 genes involved in pock formation and inviability. J Bacteriol 1991, 173(24):7975-7981.

38. Barrell D, Dimmer E, Huntley RP, Binns D, O'Donovan C, Apweiler R: The GOA database in 2009-an integrated Gene Ontology Annotation resource. Nucleic Acids Res 2009, 37(Database):D396-403.

39. Raivio TL, Silhavy TJ: Periplasmic stress and ECF sigma factors. Annu Rev Microbiol 2001, 55:591-624.

40. Helmann JD: The extracytoplasmic function (ECF) sigma factors. Adv Microb Physiol 2002, 46:47-110.

41. Alm E, Huang K, Arkin A: The evolution of two-component systems in bacteria reveals different strategies for niche adaptation. PLoS Comput Biol 2006, 2(11):e143.

42. Nett M, Ikeda H, Moore BS: Genomic basis for natural product biosynthetic diversity in the actinomycetes. Nat Prod Rep 2009, 26(11):1362.

43. Omura S, Ikeda H, Ishikawa J, Hanamoto A, Takahashi C, Shinose M, Takahashi Y, Horikawa H, Nakazawa H, Osonoe T, et al: Genome sequence of an industrial microorganism Streptomyces avermitilis: deducing the ability of producing secondary metabolites. Proc Natl Acad Sci USA 2001, 98(21):12215-12220.

44. Gust B, Challis GL, Fowler K, Kieser T, Chater KF: PCR-targeted Streptomyces gene replacement identifies a protein domain needed for biosynthesis of the sesquiterpene soil odor geosmin. Proc Natl Acad Sci USA 2003, 100(4):1541-1546.

45. Horinouchi S: Mining and polishing of the treasure trove in the bacterial genus Streptomyces. Biosci Biotechnol Biochem 2007, 71(2):283-299.

46. Horinouchi S: A microbial hormone, A-factor, as a master switch for morphological differentiation and secondary metabolism in Streptomyces griseus. Front Biosci 2002, 7:D2045-D2057.

47. Ohnishi Y, Yamazaki H, Kato JY, Tomono A, Horinouchi S: AdpA, a central transcriptional regulator in the A-factor regulatory cascade that leads to morphological development and secondary metabolism in Streptomyces griseus. Biosci Biotechnol Biochem 2005, 69(3):431-439.

48. Du YL, Li SZ, Zhou Z, Chen SF, Fan WM, Li YQ: The pleitropic regulator AdpAch is required for natamycin biosynthesis and morphological differentiation in Streptomyces chattanoogensis. Microbiology 2011, 157(Pt 5):1300-1311.

49. Bibb MJ: Regulation of secondary metabolism in streptomycetes. Curr Opin Microbiol 2005, 8(2):208-215.

50. Zhang W, Ferreira JP, Tang Y: Regulation of Secondary Metabolism in Bacteria. In The Metabolic Pathway Engineering Handbook -Fundamentals. Boca Raton: CRC press;Smolke CD 2009:13.01-13.26.

51. Umeyama T, Lee PC, Ueda K, Horinouchi S: An AfsK/AfsR system involved in the response of aerial mycelium formation to glucose in Streptomyces griseus. Microbiology 1999, 145(Pt 9):2281-2292.

52. Zhuo Y, Zhang W, Chen D, Gao H, Tao J, Liu M, Gou Z, Zhou X, Ye BC, Zhang $\mathrm{Q}$, et al: Reverse biological engineering of hrdB to enhance the 
production of avermectins in an industrial strain of Streptomyces avermitilis. Proc Natl Acad Sci USA 2010, 107(25):11250-11254.

53. Mao XM, Zhou Z, Hou XP, Guan WJ, Li YQ: Reciprocal regulation between SigK and differentiation programs in Streptomyces coelicolor. J Bacteriol 2009, 191(21):6473-6481.

54. Mao XM, Zhou Z, Cheng LY, Hou XP, Guan WJ, Li YQ: Involvement of SigT and RstA in the differentiation of Streptomyces coelicolor. FEBS Lett 2009, 583(19):3145-3150.

55. Chakraburtty R, Bibb M: The ppGpp synthetase gene (relA) of Streptomyces coelicolor A3(2) plays a conditional role in antibiotic production and morphological differentiation. J Bacterio/ 1997, 179(18):5854-5861.

56. Margolin W: FtsZ and the division of prokaryotic cells and organelles. Nat Rev Mol Cell Biol 2005, 6(11):862-871.

57. Wang L, Yu Y, He X, Zhou X, Deng Z, Chater KF, Tao M: Role of an FtsKlike protein in genetic stability in Streptomyces coelicolor A3(2). J Bacteriol 2007, 189(6):2310-2318.

58. Mazza P, Noens EE, Schirner K, Grantcharova N, Mommaas AM, Koerten HK, Muth G, Flärdh K, Van Wezel GP, Wohlleben W: MreB of Streptomyces coelicolor is not essential for vegetative growth but is required for the integrity of aerial hyphae and spores. Mol Microbiol 2006, 60(4):838-852.

59. Heichlinger A, Ammelburg M, Kleinschnitz EM, Latus A, Maldener I, Flardh K, Wohlleben W, Muth G: The MreB-Like Protein Mbl of Streptomyces coelicolor A3(2) Depends on MreB for Proper Localization and Contributes to Spore Wall Synthesis. J Bacteriol 2011, 193(7):1533-1542.

60. Yamazaki H, Ohnishi Y, Horinouchi S: An A-factor-dependent extracytoplasmic function sigma factor (sigma(AdsA)) that is essential for morphological development in Streptomyces griseus. J Bacteriol 2000, 182(16):4596-4605.

61. Yamazaki H, Ohnishi Y, Horinouchi S: Transcriptional switch on of ssgA by A-factor, which is essential for spore septum formation in Streptomyces griseus. J Bacteriol 2003, 185(4):1273-1283.

62. den Hengst CD, Tran NT, Bibb MJ, Chandra G, Leskiw BK, Buttner MJ: Genes essential for morphological development and antibiotic production in Streptomyces coelicolor are targets of BldD during vegetative growth. Mol Microbiol 2010, 78(2):361-379.

63. Kelemen GH, Brown GL, Kormanec J, Potuckova L, Chater KF, Buttner MJ: The positions of the sigma-factor genes, whiG and sigF, in the hierarchy controlling the development of spore chains in the aerial hyphae of Streptomyces coelicolor A3(2). Mol Microbiol 1996, 21(3):593-603.

64. Driessen AJ, Nouwen N: Protein translocation across the bacterial cytoplasmic membrane. Annu Rev Biochem 2008, 77:643-667.

65. Widdick DA, Dilks K, Chandra G, Bottrill A, Naldrett M, Pohlschroder M, Palmer T: The twin-arginine translocation pathway is a major route of protein export in Streptomyces coelicolor. Proc Natl Acad Sci USA 2006, 103(47):17927-17932.

66. Joshi MV, Mann SG, Antelmann H, Widdick DA, Fyans JK, Chandra G, Hutchings MI, Toth I, Hecker M, Loria R, et al: The twin arginine protein transport pathway exports multiple virulence proteins in the plant pathogen Streptomyces scabies. Mol Microbiol 2010, 77(1):252-271.

67. Ramos JL, Martinez-Bueno M, Molina-Henares AJ, Teran W, Watanabe K, Zhang X, Gallegos MT, Brennan R, Tobes R: The TetR family of transcriptional repressors. Microbiol Mol Biol Rev 2005, 69(2):326-356.

68. Haydon DJ, Guest JR: A new family of bacterial regulatory proteins. FEMS Microbiol Lett 1991, 63(2-3):291-295.

69. Sunnarborg A, Klumpp D, Chung T, LaPorte DC: Regulation of the glyoxylate bypass operon: cloning and characterization of iclR. J Bacteriol 1990, 172(5):2642-2649.

70. Kirby R: Chromosome diversity and similarity within the Actinomycetales. FEMS Microbiol Lett 2011, 319(1):1-10.

71. Hopwood DA: Soil to genomics: the Streptomyces chromosome. Annu Rev Genet 2006, 40:1-23.

72. Zhou Z, Gu J, Du YL, Li YQ, Wang Y: The -omics Era- Toward a SystemsLevel Understanding of Streptomyces. Curr Genomics 2011, 12(6):404-416.

73. Xu D, Seghezzi N, Esnault C, Virolle MJ: Repression of antibiotic production and sporulation in Streptomyces coelicolor by overexpression of a TetR family transcriptional regulator. Appl Environ Microbiol 2010, 76(23):7741-7753

74. Weickert MJ, Adhya S: A family of bacterial regulators homologous to Gal and Lac repressors. J Biol Chem 1992, 267(22):15869-15874.
75. Lamb DC, Guengerich FP, Kelly SL, Waterman MR: Exploiting Streptomyces coelicolor A3(2) P450s as a model for application in drug discovery. Expert Opin Drug Metab Toxicol 2006, 2(1):27-40.

76. Zhao B, Waterman MR: Novel properties of P450s in Streptomyces coelicolor. Drug Metab Rev 2007, 39(2-3):343-352.

77. Lu YW, San Roman AK, Gehring AM: Role of phosphopantetheinyl transferase genes in antibiotic production by Streptomyces coelicolor. J Bacteriol 2008, 190(20):6903-6908.

78. Walker JB: Enzymatic synthesis of aminocyclitol moieties of aminoglycoside antibiotics from inositol by Streptomyces spp.: detection of glutamine-aminocyclitol aminotransferase and diaminocyclitol aminotransferase activities in a spectinomycin producer. J Bacteriol 1995, 177(3):818-822.

79. Erb A, Weiss H, Harle J, Bechthold A: A bacterial glycosyltransferase gene toolbox: generation and applications. Phytochemistry 2009, 70(1516):1812-1821

80. Mendez C, Salas JA: The role of $A B C$ transporters in antibiotic-producing organisms: drug secretion and resistance mechanisms. Res Microbiol 2001, 152(3-4):341-350

81. Saier MH Jr, Yen MR, Noto K, Tamang DG, Elkan C: The Transporter Classification Database: recent advances. Nucleic Acids Res 2009, 37(Database):D274-278.

82. Johnson M, Zaretskaya I, Raytselis Y, Merezhuk Y, McGinnis S, Madden TL: NCBI BLAST: a better web interface. Nucleic Acids Res 2008, 36(Web Server):W5-9.

83. Larkin MA, Blackshields G, Brown NP, Chenna R, McGettigan PA, McWilliam H, Valentin F, Wallace IM, Wilm A, Lopez R, et al: Clustal W and Clustal X version 2.0. Bioinformatics 2007, 23(21):2947-2948.

84. Tamura K, Peterson D, Peterson N, Stecher G, Nei M, Kumar S: MEGA5 Molecular Evolutionary Genetics Analysis using Maximum Likelihood, Evolutionary Distance, and Maximum Parsimony Methods. Mol Biol Evol 2011.

85. Darling AE, Mau B, Perna NT: progressiveMauve: multiple genome alignment with gene gain, loss and rearrangement. PLOS One 2010, 5(6) e11147.

doi:10.1186/1471-2105-13-S10-S8

Cite this article as: Zhou et al:: Genome plasticity and systems evolution in Streptomyces. BMC Bioinformatics 2012 13(Suppl 10):S8.

\section{Submit your next manuscript to BioMed Central and take full advantage of:}

- Convenient online submission

- Thorough peer review

- No space constraints or color figure charges

- Immediate publication on acceptance

- Inclusion in PubMed, CAS, Scopus and Google Scholar

- Research which is freely available for redistribution

Submit your manuscript at www.biomedcentral.com/submit
C Bïomed Central 